\title{
Biomechanics of the pulmonary autograft valve in the aortic position
}

\author{
ANDRZEJ GORCZYNSKI, MIECZYSŁAW TRENKNER, LECH ANISIMOWICZ, \\ ROMUALD GUTKOWSKI, ANTONI DRAPELLA, EWA KWIATKOWSKA, \\ MAREK DOBKE
}

From the Institute of Surgery, Medical Academy, Gdanisk, and Technical University, Gdanisk, Poland

ABSTRACT Pulmonary autograft valve replacement has been simulated by implanting the pulmonary valve into the aortic position of the same cadaver heart from both human and porcine sources. The forces acting on the pulmonary valve leaflets have been calculated on the basis of a triaxial ellipsoid mathematical model. These forces on the pulmonary autograft valve were shown to be essentially similar to those previously reported for aortic valve leaflets. Biomechanical measurements have been made on the simulated autograft valves and on the isolated pulmonary valve cusps. The tensile strengths of the pulmonary valve cusps in both circumferential and radial directions were roughly three times greater than those of aortic valve cusps. This indicated the ability of the pulmonary valves to accept, ab initio, aortic valve closing pressures. Pressureinduced changes in dimension, calculated on the basis of diameters of the simulated pulmonary autograft root, also indicated that the distensibility of the autograft valve was limited. It reached a maximum at $30 \mathrm{~mm} \mathrm{Hg}(4 \mathrm{kPa})$ without any suggestion of further distension to the point of distortion and incompetence. The combination of the calculated forces acting on the valve and the biomechanical measurements have shown that pulmonary valves used as autograft aortic valve replacements are able to tolerate aortic pressures from the time of implantation. These experimental results from simulated autografts support the clinical use of this valve over the past 13 years.

Aortic valve replacement with an autograft pulmonary valve was first described by Ross. ${ }^{1}$ In this procedure for isolated aortic valve disease the damaged valve in the systemic circulation was replaced with an autologous, living pulmonary valve and the lowpressure pulmonary circulation then received a homograft or xenograft valve. The advantages of the pulmonary autograft valve are that it is viable, autogenous, sterile, and implanted without any modifications, so retaining its natural design and function. ${ }^{2}$ Autograft valves combine all the advantages of homograft valves without the inevitability of degeneration and subsequent incompetence. The lack of degenerative changes has been seen in pulmonary autograft valves removed for technical reasons.

The procedure was introduced primarily for children and adolescents, in whom the growth potential of the pulmonary autograft might be realised; but its

Address for reprint requests: Dr Andrzej Gorczynski, Institute of Surgery, 80-211 Gdansk, ul.Dębinki 7, Poland. value has also been confirmed in adults. The original insertion technique ${ }^{1}$ was identical to that used for homograft aortic valves, ${ }^{3}$ but the technique was changed in $1976 . .^{2}$ In this modified technique the pulmonary valve is inserted into the aorta as a cylinder, and the coronary ostia are anastomosed to openings made in the cylinder.

Long-term results over 10 years have confirmed the excellent results obtained with the pulmonary autograft valve. ${ }^{25}$ Such results reflect the clinical acceptability of this approach but no attempt has been made to present a biomechanical explanation for the success of the pulmonary autograft valve (DN Ross, personal communication). Previous studies on the geometry and function of the aortic valve $^{6}$ have been used as the basis for an evaluation of the pulmonary valve when used as an autogenous valve replacement.

\section{Methods}

Fifty-five fresh human hearts and 70 fresh porcine 
hearts were used, the porcine hearts serving as a basis for solving the technical problems associated with an in vitro simulation of autografting the pulmonary valve into the aortic area. The distensibility of the aortic and pulmonary valve roots was measured over pressure ranges of $0-150$ and $0-100$ $\mathrm{mm} \mathrm{Hg}$ (up to 20 and $13.3 \mathrm{kPa}$ ) respectively. The circumferences were measured at the lowest points of leaflet attachment (lower diameter) and at the level of the commissures (upper diameter). The lower circumference was measured directly and the diameter calculated. Bulging of the sinuses of Valsalva under pressure made direct measurement of the upper circumference impossible so an indirect measurement was made from the circle circumscribing the triangle formed by the three commissures, as in figure 1 . The upper diameter was then calculated.

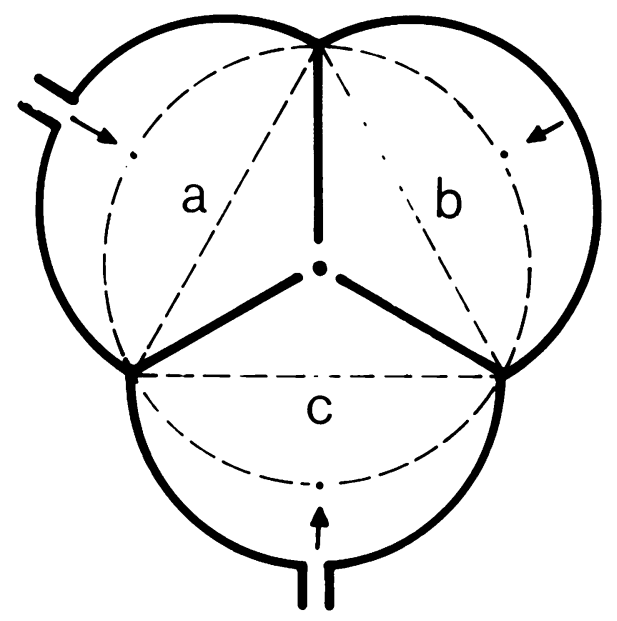

$O=\frac{\pi a b c}{2 \sqrt{ }(p-a)(p-b)(p-c)}$

$p=\frac{a+b+c}{2}$

Fig 1 Method used for the indirect measurement of the upper diameter of a valve at the commissural level. The letter $O$ is the symbol of the upper diameter of the valve at the commissural level derived from the mathematical formula of the triangle encircled with a circle. The letters $a$, $b, c$ are arms of this triangle.

The technique for autograft implantation was simulated by enclosing the pulmonary artery root within the aortic root from the same heart, two rows of continuous $3 / 0$ Mersilene being used. The valve leaflets were marked with $5 / 0$ multifilament steel sutures at the commissures, the corpora Aurantii, and the lowest point of the leaflet attachment.
The breaking strain of pulmonary valve leaflets was measured with an FC1c testing machine (VEB Messgerate, Leipzig). Rectangular strips were cut from the leaflet in both circumferential and radial directions. The minimum width of the strip was $5 \mathrm{~mm}$ and the thickness varied from 0.10 to $0.50 \mathrm{~mm}$. Tensile strengths were calculated from the breaking strains per unit area. Circumferential distension is effectively a parallel force, and is designated $\mathrm{N} \Theta$, and radial distension is a meridional


the calculation of the forces acting on the leaflet. These calculations used a simplified mathematical model of the valve in which a triaxial ellipsoid corresponds to the shape of the leaflet. This model is derived from radiographic features of the simulated autograft at different pressures and from direct measurements of the aortic root.

Each leaflet is assumed to be part of the envelope of the triaxial ellipsoid and boundary conditions resulting from any discontinuity of the envelope are ignored, so that the existence of the free margin of each leaflet is neglected. The anisotropy and the distensibility of the elements of the valve are included in the calculations by application of the theory of thin-walled membranes, but the bending forces are excluded since the studies all relate to the diastolic phase of the valve cycle. The forces that operate in the envelope of a triaxial ellipsoid may be considered in three planes: $A B$, the plane of the leaflet attachment; AC, the sagittal section of the leaflet; and $\mathrm{BC}$, along the free margin of the leaflet (fig 2).

The forces acting on the valve resulting from meridional and circumferential distension were calculated on the basis of the theory of figural deformation according to the hypothesis of Huber. ${ }^{7}$ Details of the mathematical model have been fully described elsewhere. ${ }^{689}$

\section{Results}

The distensibility, in terms of the increase in diameter, for aortic and pulmonary valve roots is shown in figure 3. It is clear that, while the pulmonary valve at the level of the commissures (upper diameter) is considerably more distensible than is the aortic valve, the pulmonary valve ring is less distensible than is the aortic ring. When the pulmonary valve is examined as a simulated autograft within the aortic root, however, the greater distensibility is effectively contained and there is a noticeable cut-off in distensibility of the simulated autograft valve above pressures of $30 \mathrm{~mm} \mathrm{Hg}$ (fig 4). The constrained distensibility of a simulated autograft valve results in an increase in the area of coaptation of the valve. 




Fig 2 Diagram to show the three planes $A B, A C$, and $B C$ in which the forces of distension act on a pulmonary valve in diastole. Each leaflet of the valve is considered as part of the envelope of the triaxial ellipsoid in this figure and the calculated forced are derived from the angles $\theta$ and $\boldsymbol{D}=$. ( $\theta=$ circumferential and 10 radial distension).
Derived values for the forces acting on four sectors in three planes of the triaxial ellipsoid of the simulated autograft valves are presented in table 1 . These forces have been calculated for both circumferential (NO) and radial (ND) distensions and their values and distribution are very similar to those previously reported for the aortic valve. ${ }^{10}$

Although the breaking strain for the aortic and pulmonary valve leaflets was roughly the same (table 2), the thinner pulmonary valve leaflets had a greater tensile strength (table 3 ). The human pulmonary valve leaflets were 2.6 times stronger than those of the aortic valve, and for the porcine hearts the ratio was $3 \cdot 6: 1$.

\section{Discussion}

The relative rigidity of the pulmonary artery root at pressures above $30 \mathrm{~mm} \mathrm{Hg}$ is shown in figure 3 as the "lower diameter" values. This non-distensibility must be a major factor in maintaining the competence of the pulmonary valve in pulmonary hypertension.

The constraints imposed on the pulmonary valve in the simulated autograft cause it to assume the geometry of the aortic valve (fig 4). The forces acting on such a simulated autograft have been shown to be the same as those acting on the aortic valve. ${ }^{10}$ Since the forces are the same and the geometry is similar the remaining factor that can ensure the integrity of the simulated autograft is the tensile strength of the leaflets. The breaking strain of pulmonary valve leaflets was very similar to that of aortic leaflets (table 2) but the thinner pulmonary valve leaflets were almost three times stronger (table 3 ).

Parallel experiments with porcine hearts have shown a similar differential in tensile strength be-

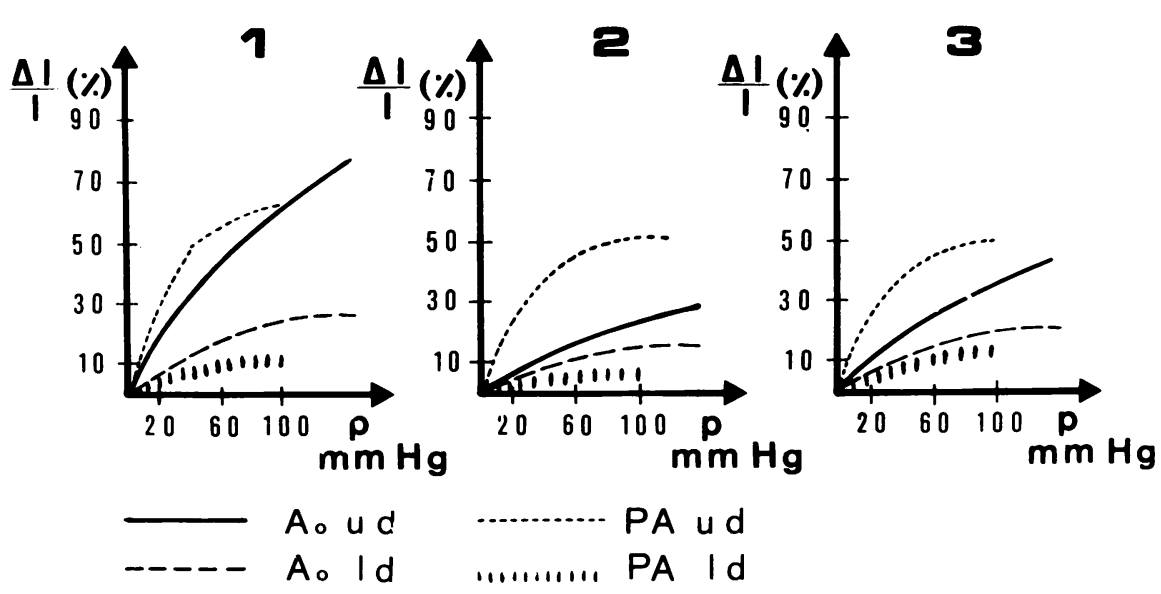

Fig 3 Distensibility of three typical aortic and three typical pulmonary valves at "lower" and "upper" diameters. The graphs show the percentage chang: in diameter $(\Delta I / 1 \%)$ for an increase in pressure. ld = lower diameter; ud = upper diameter; $A o$ = aortic valve; $P A=$ pulmonary valve. 
Table 1 Values of forces operating in the pulmonary valve leaflet in simulated pulmonary autografts (human hearts); values are expressed in grams and negative values are compressive forces

\begin{tabular}{|c|c|c|c|c|c|}
\hline & Sector & $90^{\circ}$ & $120^{\circ}$ & $150^{\circ}$ & $180^{\circ}$ \\
\hline \multirow[t]{2}{*}{$\begin{array}{l}\text { Plane of leaflet attachment (A) } \\
\text { Sagittal plane section of the leaflet (B) }\end{array}$} & $\begin{array}{l}\text { NQ } \\
\text { NO } \\
\text { NO } \\
\text { NO }\end{array}$ & $\begin{array}{r}85.06 \\
-0.92 \\
227.74 \\
-0.92\end{array}$ & $\begin{array}{r}134.96 \\
0.20 \\
178.04 \\
-0.40\end{array}$ & $\begin{array}{r}209.15 \\
1.14 \\
130.12 \\
1.58\end{array}$ & $\begin{array}{r}238 \cdot 29 \\
1 \cdot 45 \\
107 \cdot 36 \\
3.21\end{array}$ \\
\hline & Sector & $0^{\circ}$ & $30^{\circ}$ & $60^{\circ}$ & $90^{\circ}$ \\
\hline Plane of the free margin of the leaflet $(C)$ & $\begin{array}{l}\mathbf{N O} \\
\mathbf{N O}\end{array}$ & $\begin{array}{r}85.06 \\
-0.92\end{array}$ & $\begin{array}{r}120.73 \\
-0.92\end{array}$ & $\begin{array}{r}192.07 \\
-0.92\end{array}$ & $\begin{array}{r}227.74 \\
-0.92\end{array}$ \\
\hline
\end{tabular}

NФ: radial distension; $\mathrm{N} \Theta$ : circumferential distension.

Table 2 Breaking strain of valve leaflets

\begin{tabular}{|c|c|c|}
\hline \multirow[b]{2}{*}{$\begin{array}{l}\text { Human aorta circumferential } \\
\text { Human aorta parallel } \\
\text { Human pulmonary artery circumferential } \\
\text { Human pulmonary artery parallel } \\
\text { Porcine aorta circumferential } \\
\text { Porcine aorta parallel } \\
\text { Porcine pulmonary artery circumferential } \\
\text { Porcine pulmonary artery parallel }\end{array}$} & \multicolumn{2}{|c|}{$\begin{array}{l}\text { Breaking strain }(g) \\
\text { (mean } \pm S D)\end{array}$} \\
\hline & 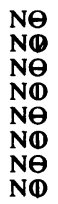 & $\begin{array}{r}206 \pm 36 \\
105 \pm 41 \\
217 \pm 38 \\
82 \pm 33 \\
215 \pm 33 \\
90 \pm 27 \\
194 \pm 43 \\
62 \pm 35\end{array}$ \\
\hline
\end{tabular}

Table 3 Tensile strength of valve leaflets

\begin{tabular}{|c|c|c|}
\hline & & $\begin{array}{l}\text { Mean tensile } \\
\text { strength } \\
\left(\mathrm{N} / \mathrm{mm}^{2}\right)\end{array}$ \\
\hline $\begin{array}{l}\text { Human aorta circumferential } \\
\text { Human aorta parallel } \\
\text { Human pulmonary artery circumferential } \\
\text { Human pulmonary artery parallel } \\
\text { Porcine aorta circumferential } \\
\text { Porcine aorta parallel } \\
\text { Porcine pulmonary artery circumferential } \\
\text { Porcine pulmonary artery parallel }\end{array}$ & 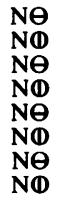 & $\begin{array}{l}0.80 \\
0.46 \\
2 \cdot 13 \\
1 \cdot 07 \\
1 \cdot 05 \\
0 \cdot 50 \\
3 \cdot 80 \\
1 \cdot 21\end{array}$ \\
\hline
\end{tabular}

Conversion: SI to traditional units $-1 \mathrm{~N} / \mathrm{mm}^{2} \approx 0.102 \mathrm{lbf} / \mathrm{in}^{2}$.

tween aortic and pulmonary valve cusps (table 3 ). It is perhaps reasonable to suggest that porcine pul- monary valves could be used in valved conduits to repair some congenital cardiac anomalies, such as severe tetralogy of Fallot and pulmonary atresia.

The greater tensile strength of the pulmonary leaflets may depend on the pattern of fibre orientation within the pulmonary valve cusps. Electron microscopical analysis will be necessary to investigate this.

The implied structural differences in the pulmonary valve cusps, which confer a greater tensile strength, may be a consequence of the higher pulmonary artery pressures during fetal development. It is clear therefore that the pulmonary cusps in an autograft valve have a sufficient reserve of strength to withstand the abrupt onset of systemic pressures. These systemic pressures are five to seven times greater than the pulmonary artery pressures. The pulmonary autograft valve is able to tolerate these pressures from the moment of implantation. The growth potential of the viable autograft valve affords an opportunity for further adaptation to the conditions within the aortic root. The increased oxygen saturation of the systemic circulation may also influence any adaptation of the autograft valve to the systemic environment. These results show that the suitable geometry of the simulated autograft valve and the greater tensile strength of the leaflets,
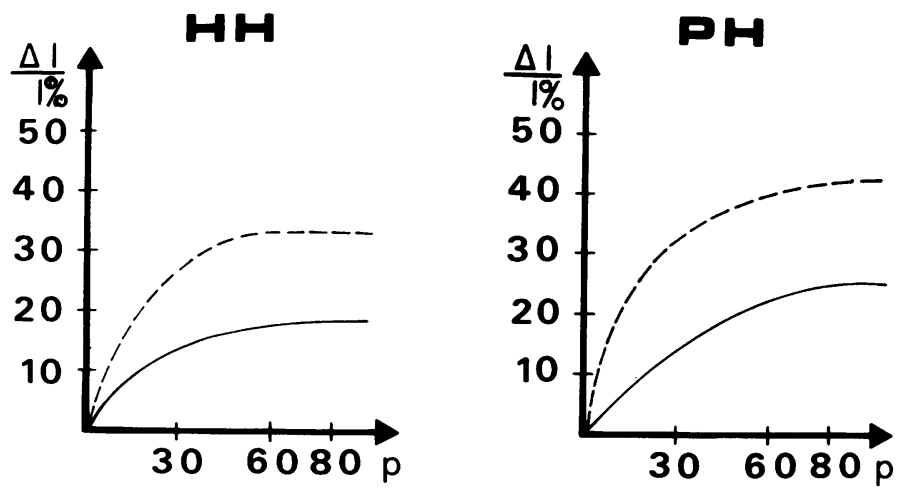

Fig 4 Distensibility at the "upper" diameter of two simulated pulmonary autografts, expressed as change in diameter $(\Delta I / 1 \%)$ with changes in pressure. $\mathrm{HH}=$ human heart; $\boldsymbol{P H}=$ porcine heart. Broken line is pulmonary valve; solid line is aortic valve. 
together with the growth and adaptation potential of the viable pulmonary autograft valve, are all essential factors for the success of this unique procedure conceived by Ross in 1967 .

\section{References}

' Ross DN. Replacement of aortic and mitral valves with a pulmonary autograft. Lancet 1967 ;ii:956-7.

${ }^{2}$ Ross DN, Martelli V, Wain WH. Allograft and autograft valves used for aortic valve replacement. In: Ionescu MI, ed. Tissue heart valves. London: Butterworths, 1979.

${ }^{3}$ Ross DN. Homograft replacement of the aortic valve. Lancet 1962;ii:487.
4 Bodnar E, Wain WH, Martelli V, Ross DN. Long term performance of 580 homograft and autograft valves used for aortic valve replacement. Thorac Cardiovasc Surg 1979;27:31-8.

${ }^{5}$ Gula G, Wain WH, Ross DN. Ten years experience with pulmonary autograft replacements for aortic valve disease. Ann Thorac Surg 1979;28:322-6.

- Trenkner M, Raczynski S, Gutkowski R. Optimal diameter of the stent for aortic valvular grafts. J Thorac Cardiovasc Surg 1976;72:613-7.

${ }^{7}$ Huber MT. Teoria sprezystosci. Warsaw: PWN Warszawa, 1954.

- Gorczynski A. Geometria i funkcja zastawki tetnicy płucnej w aspeckie jej autoprzeszczepienia w ujscie tẹtnicy głbwnej. Thesis, Gdansk Medical Academy, 1979.

- Trenkner M. Kompleksowe badania homo i heterografiow aortalnych. Thesis, Gdańsk Medical Academy, 1974. 